\title{
PRÓDROMO DE LA FLORA ACUÁTICA ESPAÑOLA: AGUAS LENÍTICAS
}

\author{
S. Cirujano, M. Velayos \& F. Castilla \\ Real Jardín Botánico, C.S.I.C. Plaza de Murillo, 2. 28014 Madrid
}

Palabras clave: Flora acuática, España

\begin{abstract}
During the very last years many bibliographic references on water plants has been published. At this moment, it is essential the use of computers to compilate not only chorological data but also bibliographic, ecological and taxonomic information.

In this paper we present the firsts results of a data base (with 19.000 records) obtained from 900 articles. This Data Base of Water-Plants, involve 128 taxa (119 species and 39 genera) of vascular plants from Spain. Next goal must be the edition of Aquatic Flora of Spain.
\end{abstract}

\section{INTTRODUCCIÓN}

La bibliografía existente sobre la flora acuática española ha aumentado considerablemente durante los últimos años. No obstante, la fiabilidad de las identificaciones es en muchos casos débil. Los errores y las determinaciones incorrectas se han transmitido de publicación en publicación, y es difícil a veces discernir la veracidad de algunos datos o referencias. En esta situación parece adecuado plantearse la realización de un Pródromo de la Flora Acuática Española.

\section{MATERIAL Y MÉTODOS}

Para afrontar la redacción de un Pródromo que reuna los macrófitos que viven en las aguas de la España peninsular y las Islas Baleares, resulta imprescindible una recopilación bibliográfica exhaustiva que recoja todas las citas existentes.

La premisa básica consiste en definir que táxones deben incluirse en este Pródromo, es decir, que es lo que entendemos por plantas acuáticas. En este sentido nos hemos remitido a la definición que dan Den Hartog \& Segal (1964): "Se entiende por planta acuática aquella que es capaz de completar su ciclo biológico cuando todas sus partes están sumergidas o mantenidas por el agua (hojas flotantes) ${ }^{n}$. Esta definición excluye a los helófitos, entre los que se encuentran el carrizo [Phragmites australis (Cav.) Trin. ex Steudel ], la espadaña (Typha sp. pl.), la mayoria de las ciperáceas, y otras plantas mas pequeñas pero con similares apetencias ecológicas.

En segundo lugar debe tenerse en cuenta la calidad de la información bibliográfica. Se ha recopilado exclusivamente aquella información que tiene un grado de fiabilidad elevado (aportada por especialistas o respaldada por testimonios de herbario) y las referencias de fiabilidad media (realizada por botánicos o autores de solvencia reconocida).

Basándonos en estas dos premisas, el Pródromo de la Flora Acuática comprende tres fases esenciales: elaboración de una base de datos bruta (BDB), transformación en una base de datos depurada (BDD), y confección de un catálogo de plantas acuáticas españolas. Estas tres fases culminan en la edición de la Flora Acuática Española.

En la BDB se han incluido las citas de macrófitos acuáticos que aparecen en trabajos monográficos y en revistas nacionales y extranjeras. En total se ha vaciado la información contenida en los volúmenes correspondientes a 74 publicaciones periódicas, 
que junto a las monografías completan un total aproximado de 900 trabajos y cerca de 19.000 regristros. La BCB está separada en cuatro bases de datos que agrupan distintos tipos de medios acuáticos:

LOCI_A.DBF - Lagos, lagunas y humedales interiores. 2007 localidades.

LOCI B.DBF - Aguas lóticas. 1783 localidades.

LOCIC.DBF - Ambientes litorales. 559 localidades.

LOCI_D.DBF - Pantanos y embalses. 205 localidades.

A partir de esta BDB se genera información de muy distinta índole entre la que hay que destacar la siguiente:

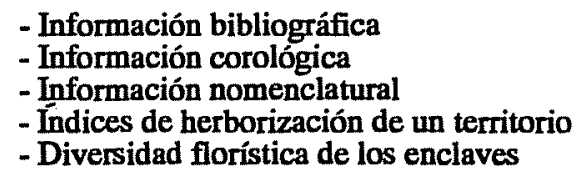

La formación de la BDB es un proceso laborioso que implica una revisión nomenclatural de los nombres recopilados, para concretar cuales son los válidos y prioritarios para cada taxon. Junto a géneros cuya taxonomía y nomenclatura es suficientemente conocida en nuestro país (Potamogeton, Zannichellia, Ruppia, Althenia, etc.), hay otros cuya problemática debe abordarse a corto plazo. La revisión del material de herbario y las monografías disponibles permiten en muchos casos aclarar la correcta asignación de los táxones.

De este modo se obtiene una base de datos depurada (BDD) que contiene exclusivamente información contrastada o de alta fiabilidad. La BDD proporciona los siguientes datos:

- Nombres válidos de las plantas acuáticas

- Sinonimias

- Catálogo de la flora acuática

- Valoración de las localidades basada en criterios botánicos

\section{LA FLORA ACUÄTICA DE LAS AGUAS LENITICAS}

El Pródromo de la flora de las aguas leníticas está formado por la información depurada contenida en los ficheros LOCI A.DBF + LOCI C.BDF + LOCI D.DBF. En estos ficheros se encuentra, en la actualidāad, la información concerniente a $\mathbf{1} 28$ táxones que se incluyen en 119 especies y 39 géneros distribuidos en los siguientes grupos:

\section{Carófitos}

Chara, Nitella, Nitellopsis, Tolypella, Lamprothamnium

Hepáticas

Riccia, Ricciocarpos, Riella

Pteridófitos

Azolla, Isoetes, Salvinia 
Angiospermas

Callitriche, Ceratophyllum, Groenlandia, Hippuris, Myriophyllum, Nuphar, Nymphaea, Polygonum, Ranunculus, Trapa, Utricularia, Hydrocharis, Juncus, Althenia, Cymodocea, Eichornia, Elodea, Lemna, Luronium, Najas, Posidonia, Potamogeton, Ruppia, Sparganium, Spirodella, Wolffia, Zannichellia, Zostera.

La depuración de esta información permite definir los siguientes apartados:

A.- Errores en la identificación.

Bajo este epígrafe se incluyen las citas de plantas mal determinadas y que se refieren a táxones que pertenecen a nuestra flora acuática. Como ejemplos indicamos los casos de Ruppia cirrhosa (Petagna) Grande y Ranunculus aquatilis L. En el primero, las referencias de dicha planta de los enclaves salinos continentales deben asignarse a Ruppia drepanensis Tineo (Cirujano \& al., 1990). En el segundo, las numerosas citas de $R$. aquatilis son en un porcentaje muy elevado determinaciones erróneas de alguna de las subespecies de $R$. peltatus Schrank (Velayos, 1988).

También se consideran aquí las citas equivocadas de plantas que son ajenas a nuestra flora acuática. En esta situación se encuentran por ejemplo Potamogeton caespitosus Nolte, $P$. acutifolius Link., Ranunculus circinatus Sibth., $R$. fluitans Lam. y $R$. rionii Lagger. En algunas ocasiones, al existir testimonios de herbario, puede corregirse la asignación. Así, podemos resolver que el $P$. caespitosus citado por Vayreda en el lago de Bañolas (Vayreda, 1931), es en realidad $P$. pectinatus L. (García Murillo, 1990).

\section{B.- Especies introducidas.}

Este apartado se refiere exclusivamente a las plantas alóctonas no naturalizadas en nuestro país, como son Elodea canadensis Michx o el neófito Najas gracillima (A. Braun ex Engelm.) Magnus. En este sentido, Azolla caroliniana Willd. y Salvinia natans (L.) All. ambas originarias de América, deben considerarse como elementos propios de nuestra flora.

\section{C.- Especies que han de buscarse.}

Se incluyen en este apartado aquellos táxones cuya presencia es probable aunque no confirmada y las plantas muy poco frecuentes en nuestro territorio, de las que se conocen citas puntuales. Debido a que muchas de nuestras zonas húmedas han sufrido alteraciones importantes durante los últimos años, estas referencias tienen que confirmarse con nuevas recolecciones. Es el caso de Chara oedophvlla Feldmann o Trapa natans $\mathrm{L}$.

\section{CONCLUSIONES}

El Pródromo de la Flora Acuática Española pretende construir unas bases fiables para abordar la realización de la flora acuática de nuestro país.

En la fase de recopilación bibliográfica, prácticamente concluida, se separan las citas que se refieren a los medios leníticos y lóticos. La revisión de la información contenida en estos dos apartados permitirá la publicación de una lista crítica de los macrófitos acuáticos españolas. El diseño informático utilizado ofrece la posibilidad de elaborar índices con los que valorar la importancia de los táxones y de los enclaves estudiados. La inclusión en el banco de datos de los datos químicos disponibles, permite además conocer mejor la autoecología de algunas especies. 


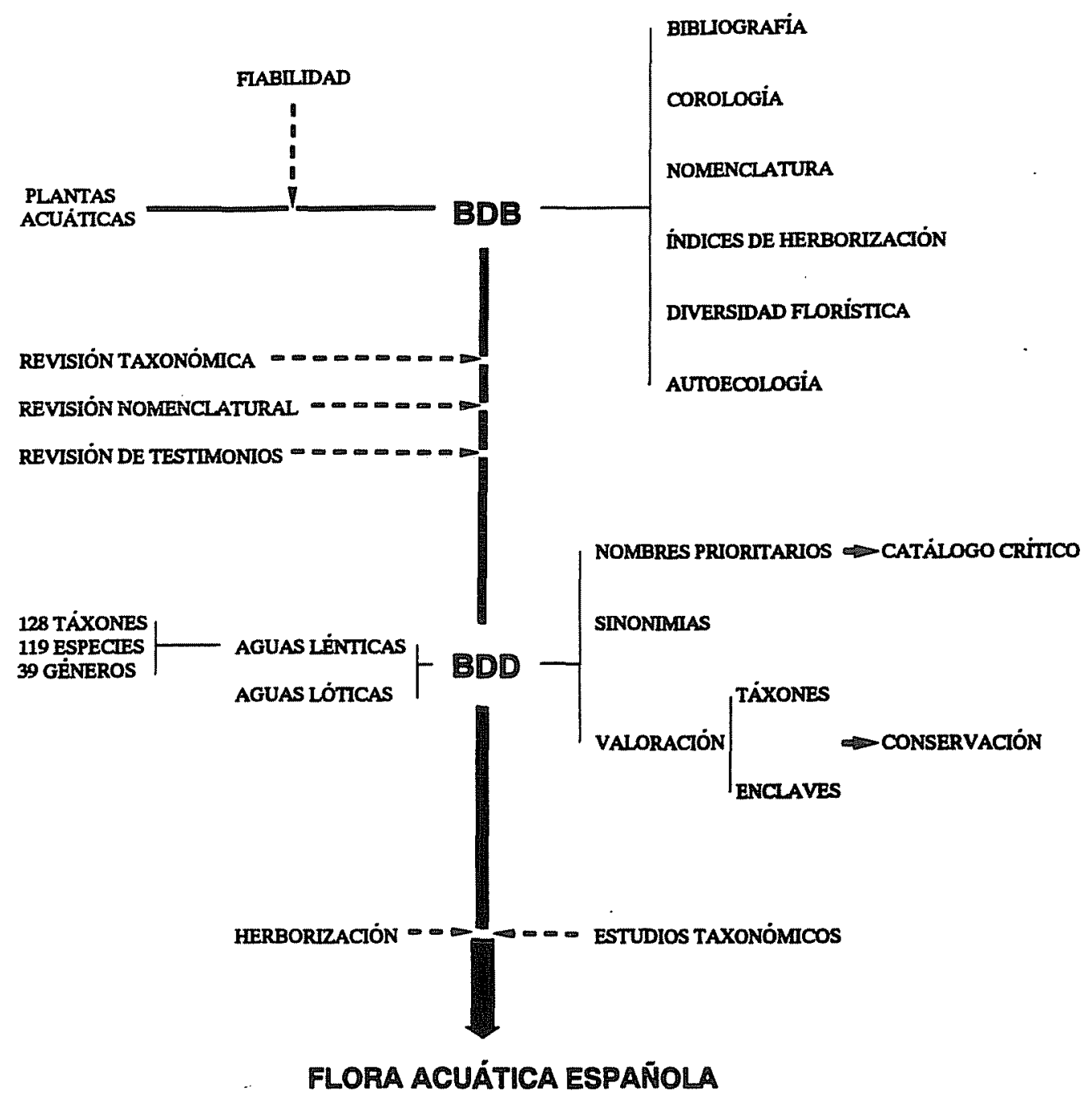

Fases del Pródromo de la Flora Acuática Española 


\section{AGRADECIMIENTOS}

El presente trabajo se enmarca en el convenio C.S.LC. - ICONA "Criterios botánicos para la valoración de las lagunas y humedales españoles (Península Ibérica y las Islas Baleares)".

\section{BIBLIOGRAFIA}

Cirujano, S. \& P. García Murillo. 1990. Asientos para un atlas corológico de la flora occidental 16, mapas 436 y 437. Fontqueria 28. 161-165.

Den Hartog, C. \& S. Segal. 1964. A new classification of the water-plant communities. Acta Bot. Neerl. 13. 367-393.

García Murillo, P. 1990. El género Potamogeton Lo en la Península Ibérica. Publ. Universidad de Sevilla.

Vayreda, E. 1931. Plantas de Cataluña. Especies y variedades más notables que introducimos en este trabajo. Cavanillesia 4. 58-62.

Velayos, M. 1988. Acotaciones a Ranunculus subgénero Batrachium (DC.) A. Gray: tratamiento taxonómico general y estudio de la variabilidad de $R$. peltatus. Anales Jard. Bot. Madrid 45(1): 103-119. 